Article

\title{
Phosphorus Availability and Growth of Benthic Primary Producers in Littoral Lake Sediments: Are Differences Linked to Induced Bank Filtration?
}

\author{
Mikael Gillefalk ${ }^{1,2, * \mathbb{D}}$, Christiane Herzog ${ }^{3}$ and Sabine Hilt ${ }^{1}$ \\ 1 Department II, Ecosystem Research, Leibniz-Institute of Freshwater Ecology and Inland Fisheries, \\ Müggelseedamm 301, 12587 Berlin, Germany; hilt@igb-berlin.de \\ 2 Faculty VI, Planning, Building and Environment, Technical University Berlin, 10623 Berlin, Germany \\ 3 Department VI, Chemical Analytics and Biogeochemistry, Leibniz-Institute of Freshwater Ecology and \\ Inland Fisheries, Müggelseedamm 301, 12587 Berlin, Germany; herzog@igb-berlin.de \\ * Correspondence: mikaelgillefalk@gmail.com
}

Received: 17 April 2019; Accepted: 24 May 2019; Published: 27 May 2019

\begin{abstract}
Submerged macrophytes and periphyton are benthic primary producers that play an important role for several ecosystem functions of lakes. Their growth often depends on the availability of phosphorus $(\mathrm{P})$ in sediments and overlying water. This $\mathrm{P}$ availability is assumed to potentially be affected by induced bank filtration (IBF), a cost-effective method for drinking water production. In this study, we tested whether littoral sediments sampled at sites with high and low influence of IBF in a temperate eutrophic lake used for bank filtration since more than 100 years affects periphyton and macrophyte growth. Sediments differed in aerobic desorbed water-soluble phosphorus $\left(\mathrm{P}_{\mathrm{H} 2 \mathrm{O}}\right)$ and iron (Fe) content and the growth of macrophytes in sediments with a high impact of IBF was lower compared to sediments with low impact of IBF. We also found that P addition to the nutrient solution increased periphyton growth and that periphyton limited macrophyte growth. While these results point to a potential impact of IBF on $\mathrm{P}$ availability in sediments that can cascade to benthic primary producers, we could not prove mechanistic links between high rates of IBF and the lower macrophyte growth. Additional research to assure a sustainable application of this valuable drinking water production method is therefore needed.
\end{abstract}

Keywords: groundwater-surface water interaction; macrophytes; periphyton; groundwater; sedimentary phosphorous

\section{Introduction}

Benthic primary producers play an important role for biodiversity, productivity and several other ecosystem functions of lakes, but have been little studied so far compared to their planktonic counterparts [1,2]. Primary production of macrophytes and periphyton in lakes is often similar to or greater than that of phytoplankton and thus constitutes an important energy input to lake food webs [1], especially in shallow and/or small lakes [3,4]. Even in large lakes, the vast majority of species inhabit the shallow, nearshore littoral zone and most fish species exploit benthic resources [5].

Nutrient and light availability are the major bottom up controlling factors of primary production in lakes. Within stream and lake pelagic systems, nitrogen $(\mathrm{N})$ and phosphorus $(\mathrm{P})$ limitation are equivalent, however, subhabitat differences indicated that $\mathrm{P}$ limitation predominates in lake benthos [6]. $\mathrm{P}$ availability for benthic primary producers depends on $\mathrm{P}$ concentrations in both water and sediment, with sediments usually containing more P per volume than water. When $\mathrm{P}$ is limiting, both macrophytes and periphyton increase their biomass with increasing P concentrations. Above a certain threshold, however, periphyton attached to macrophytes attenuates too much light and macrophyte growth 
becomes limited by light $[7,8]$. This process has been shown to be a major mechanism of macrophyte decline during eutrophication of lakes [9].

The complex balance between $\mathrm{P}$ availability in sediments and overlying water can be affected by several factors such as redox/pH conditions, supply with organic matter and transport conditions [10], but also by groundwater influx [11]. Recently, induced bank filtration (IBF) has been suggested to potentially affect $\mathrm{P}$ availability and thus growth of benthic primary producers in lake littoral areas [12]. This cost-effective pre-treatment method has been applied since the 19th century and is expected to be increasingly used for drinking water production in the future $[13,14]$. A recent study showed that IBF in many cases promotes turbid states in shallow lakes [15].

On the one hand, IBF interrupts groundwater inflow to lakes in the area surrounding the well galleries [12]. Consequently, groundwater-induced $P$ fluxes from sediments into water, which can enhance periphyton growth $[11,16,17]$, would be interrupted. On the other hand, IBF might result in an increased flux of particulate $P$ from water into sediments by clogging with fine sand, silt or clay particles and by particulate organic matter such as planktonic algae and detritus. This process has been found to promote microbial activity in sediments affected by IBF $[18,19]$ and might thus increase $P$ availability in sediments as compared to locations unaffected by IBF. But so far, changes in P availability and consequences for benthic primary producers and their interaction in lake littoral zones affected by IBF have not been studied.

In this study, we compared the characteristics of littoral sediments sampled at sites with high and low influence of IBF in a temperate eutrophic lake used for bank filtration since more than 100 years. Subsequently, the effects of the different sediments on periphyton and macrophyte growth with and without $P$ addition were tested in laboratory studies. We hypothesized that 1) littoral lake sediments affected by bank filtration show a higher content of organic matter and consequently 2) have a higher $\mathrm{P}$ availability, 3) periphyton growth is stimulated by higher $\mathrm{P}$ availability and 4) hampers macrophyte growth when its shading impact is high. If true, bank filtration could affect the abundance and structure of different benthic primary producer groups in lake littoral areas.

\section{Materials and Methods}

\subsection{Studied Lake System and Impact of Bank Filtration}

Lake Müggelsee (Figure 1) is a flow-through lake located in south-eastern Berlin, Germany. Its surface area is $7.3 \mathrm{~km}^{2}$ and average depth is $4.9 \mathrm{~m}$ with a maximum depth of $7.9 \mathrm{~m}$ [20].

In 1905, the first groundwater wells were installed north of Lake Müggelsee, and later additional wells were installed west and south of the lake [20] (Figure 1). As groundwater is being pumped and the groundwater level drops below the lake level, lake water infiltrates through the sandy sediments of the shallow littoral lake area and continues through the subsurface until reaching the well. North of the lake, where most of the water is being pumped (Figure 2A), the groundwater level drawdown is larger than five meters (Figure 1). Groundwater abstraction rates of galleries $C$ and $D$ at the north-eastern shore were about twice as high as compared to galleries $\mathrm{E}$ and $\mathrm{F}$ at the south-western shore between 2008-2017 (Figure 2A).

After very high nutrient loadings into Lake Müggelsee during the 20th century peaking in the 1970s and 1980s, nutrient loads started dropping steeply in the beginning of the 1990s and continued reducing after year 2000 [21]. In parallel with the high nutrient loading, almost all macrophytes disappeared from Lake Müggelsee in the 1970s. After the nutrient reduction started, however, no significant recovery of macrophyte abundance and species diversity was seen for about 20 years despite increasing water transparency, especially during spring [22]. Light attenuation by high periphyton biomass was significantly contributing to this delay [23]. The macrophyte population was dominated by Stuckenia pectinata (formerly known as Potamogeton pectinatus), a species known for survival under turbid conditions in shallow littoral areas of highly eutrophic lakes [22]. Only after around 2006, macrophyte maximum colonization depth and biomass started increasing [22] due to decreasing 
periphyton biomass (unpublished data). Periphyton biomass, however, is still high (unpublished data). Since 2011/2012, the lake experienced a strong invasion of quagga mussels (Dreissena rostriformis bugensis) which significantly increased water transparency all year round facilitating the expansion of macrophytes other than S. pectinata particularly in deeper littoral areas between 2 and $4 \mathrm{~m}$ [24]. The average concentrations for total phosphorus was $66 \mu \mathrm{g} / \mathrm{L}$, total organic carbon was $6.8 \mathrm{mg} / \mathrm{L}$, dry matter was $3.9 \mathrm{mg} / \mathrm{L}$, dissolved iron was $0.01 \mathrm{mg} / \mathrm{L}$ and total iron was $0.08 \mathrm{mg} / \mathrm{L}$ for the period March 2016 to March 2017 in Lake Müggelsee (data from Leibniz-Institute of Freshwater Ecology and Inland Fisheries, Berlin, Germany).

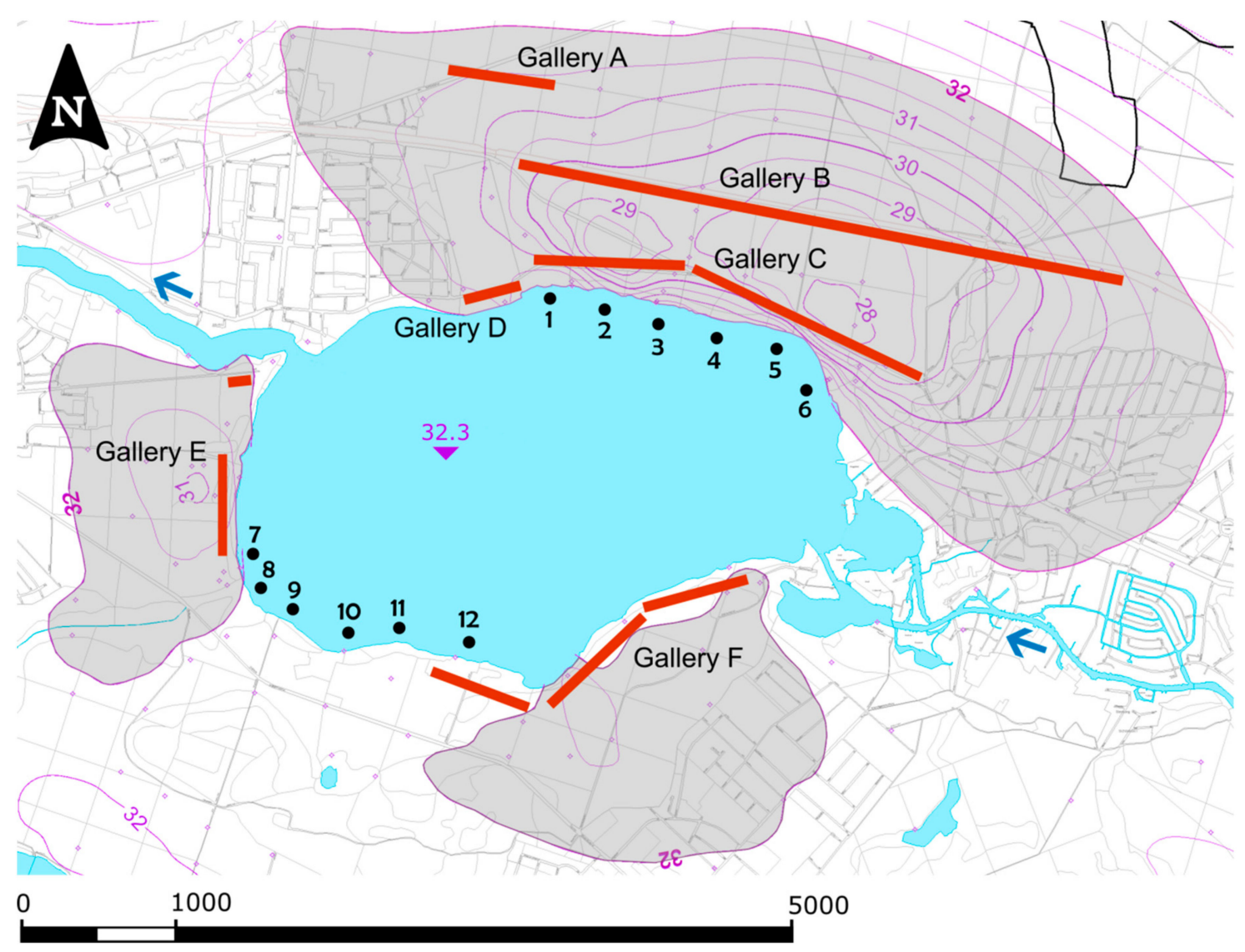

Figure 1. Sediment sample sites in Lake Müggelsee (numbered dots). Shaded area on land indicate where groundwater level is below $32 \mathrm{~m}$ above sea level (Lake Müggelsee = 32.3 MASL, purple: groundwater isolines), red thick lines indicate location of groundwater well galleries. 

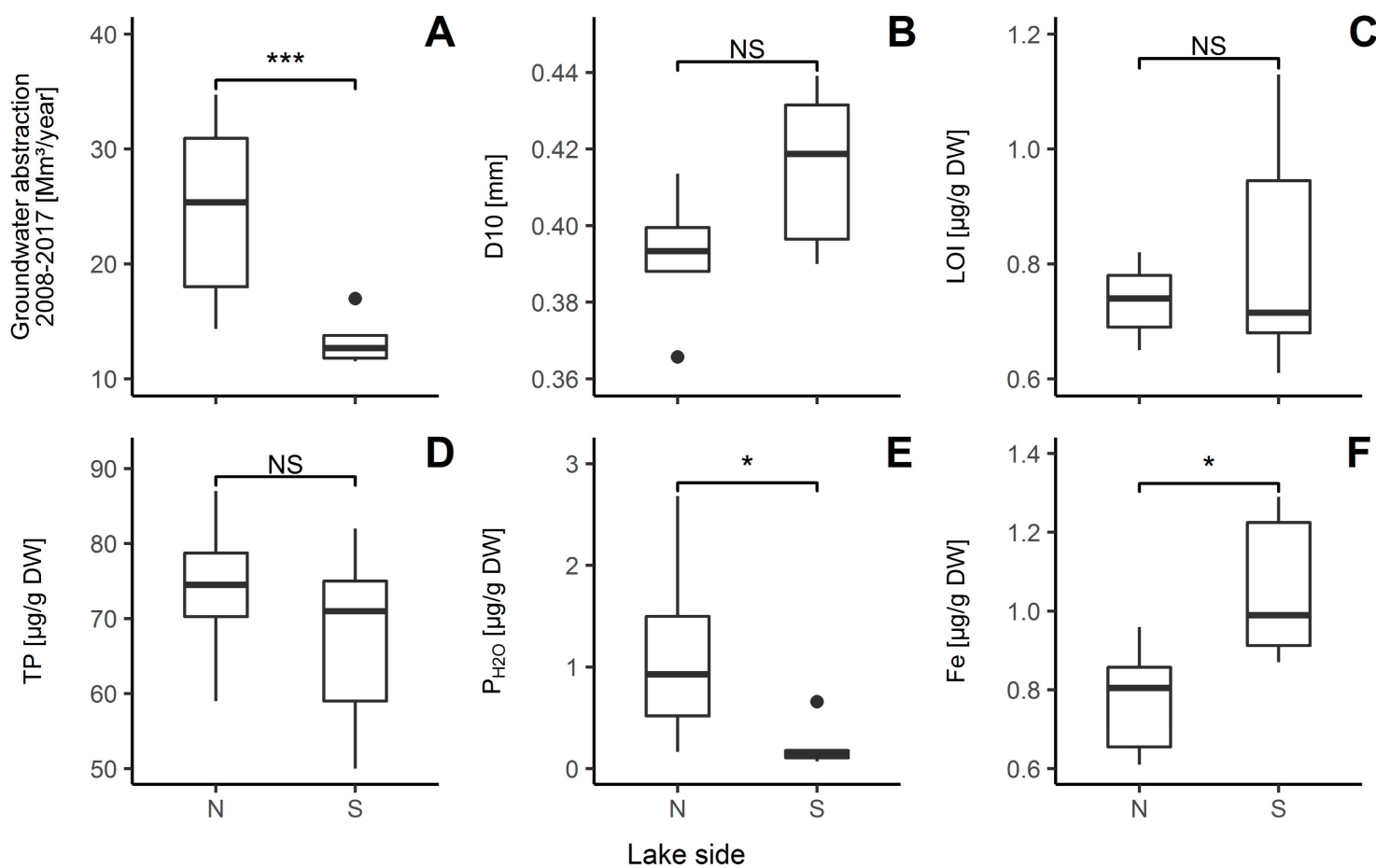

Figure 2. Groundwater abstraction rates of wells at Lake Müggelsee ((A), yearly average from 2008-2017, North-eastern (N) shore: Galleries C-D, South-western (S) shore: Galleries E-F; data from Berlin senate) and parameters of littoral sediment taken from the $\mathrm{N}$ and $\mathrm{S}$ shores (see Figure 1): Particle diameter at $10 \%$ of the cumulative weight $((\mathbf{B}), \mathrm{D} 10)$, loss on ignition at $450{ }^{\circ} \mathrm{C}((\mathbf{C}), \mathrm{LOI})$ and content of total phosphorus $((\mathbf{D}), \mathrm{TP})$, aerobic soluble phosphorus $\left((\mathbf{E}), \mathrm{P}_{\mathrm{H} 2 \mathrm{O}}\right)$ and iron $((\mathbf{F}), \mathrm{Fe}) .{ }^{*}$ Indicates a p-value $<0.05,{ }^{* * *}$ a $p$-value $<0.001$ and NS a p-value $>0.05$.

\subsection{Sampling of Sediments and Plant Tubers}

We chose six sediment sampling sites along the north-eastern $(\mathrm{N})$ shore, influenced by water abstraction through IBF (Figure 1), and six sites along the south-western (S) shore, where water abstraction is much lower than along the $\mathrm{N}$ shore (Figure 2A and Table S1). For a pre-analysis, carried out to generally characterize the sediment and to determine best practice for P analyses (see below), we took one sediment sample each from sites 5 and 10 at $1.5 \mathrm{~m}$ depth using a tube sampler attached to a push rod in February 2017. For the main analysis and growth experiment we took two samples at every site (1 to 12) at $1.5 \mathrm{~m}$ depth in March 2017.

For the growth experiment, we collected tubers from S. pectinata in 50-70 cm water depth at the $\mathrm{N}$ shore in March 2017.

\subsection{Sediment Analysis}

\subsubsection{Description}

In a pre-analysis, we analyzed two sediment layers $(0-2 \mathrm{~cm}$ and $2-6 \mathrm{~cm})$, while in the main analysis we pooled the top $5 \mathrm{~cm}$ of the two sediment cores taken at each site and used this material in the continued analysis and growth experiment. Sediment samples were very sandy and some (mostly the samples from the $S$ shore) had a 2-4 mm layer of fluffy brown organic material on top (Table S2). This upper layer and any mussels were removed in the main analyses and the growth experiment. We determined sediment dry weight by drying $10 \mathrm{~g}$ of fresh sediment sample at $105^{\circ} \mathrm{C}$ for $24 \mathrm{~h}$ and weighing them after cooling down in a desiccator. Subsequently, loss on ignition $\left(450^{\circ} \mathrm{C}\right.$ for $5 \mathrm{~h}$ ) and the grainsize distribution were determined by using the following sieve sizes: $0.063 ; 0.125 ; 0.18 ; 0.25$; $0.63 ; 1.25 ; 2.0 ; 2.8 \mathrm{~mm}$. Statistical comparison between sediments of the $\mathrm{N}$ and $\mathrm{S}$ shores was done using 
the values for D10 and D50, which are the diameters where $10 \%$ and $50 \%$ of the material's mass has a diameter smaller than the respective diameter.

\subsubsection{Phosphorus Availability}

In order to compare the content of different $P$ fractions [25], potentially relevant for macrophyte growth, and for diffusion into the overlying water affecting periphyton growth [8], we analyzed water-soluble $\mathrm{P}\left(\mathrm{P}_{\mathrm{H} 20}\right.$, aerobic, two replicates), reductive-soluble $\mathrm{P}$ ( $\mathrm{P}_{\text {reductive, }}$ anoxic, two replicates), acid-soluble $\mathrm{P}\left(\mathrm{P}_{\mathrm{HCl}}\right.$, two replicates) and total $\mathrm{P}$ (TP, five replicates). $10 \mathrm{~g}$ from each sediment sample were put into a centrifuge tube, mixed with $20 \mathrm{~mL}$ extraction solution $\left(\mathrm{H}_{2} \mathrm{O}\right.$, reductive solution $(10 \mathrm{~g}$ $\mathrm{Na}_{2} \mathrm{~S}_{2} \mathrm{O}_{4}$ and $4.6 \mathrm{~g} \mathrm{NaHCO}_{3}$ mixed with $500 \mathrm{~mL}$ distilled water) or acid solution $\left.(0.5 \mathrm{~N} \mathrm{HCl})\right)$. Total $\mathrm{P}$ was determined using $0.025 \mathrm{~g}$ grinded sample with $2 \mathrm{~mL} \mathrm{H}_{2} \mathrm{SO}_{4}$ and $2 \mathrm{~mL} \mathrm{H}_{2} \mathrm{O}_{2}$ filled to $50 \mathrm{~mL}$ with distilled water. The samples of sequential $\mathrm{P}$ extraction were shaken for $2 \mathrm{~h}$ with an overhead shaker. After centrifuging for $5 \mathrm{~min}$ (10142 g), the supernatant was decanted and subsequently filtered to $0.45 \mu \mathrm{m}$ (Minisart ${ }^{\circledR}$ NML Syringe Filter, Sartorius, Göttingen, Germany). The desorption solution was diluted when needed, digested with $\mathrm{K}_{2} \mathrm{~S}_{2} \mathrm{O}_{8}$ in the digestion tube (autoclave) and the P concentration was determined photometrically. This procedure was repeated two more times for $\mathrm{P}_{\mathrm{H} 2 \mathrm{O}}$ and $\mathrm{P}_{\text {reductive }}$, three more times for $\mathrm{P}_{\mathrm{HCl}}$ and no more for TP: $20 \mathrm{~mL}$ extraction solution, $2 \mathrm{~h}$ shaking with overhead shaker, 5 min centrifuge, filtered, digestion and photometric measurement.

Wünscher [26] used water soluble $\mathrm{P}$ as a measure for plant available $\mathrm{P}$. We took a similar approach based on the results from the pre-analysis (Figure S1) and chose $\mathrm{P}_{\mathrm{H} 2 \mathrm{O}}$ to measure $\mathrm{P}$ availability for

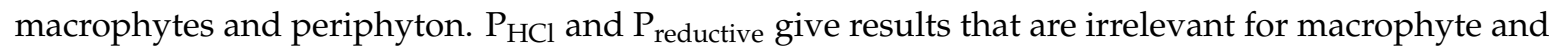
especially periphyton available $\mathrm{P}$, but TP was analyzed to see if a difference in $\mathrm{P}_{\mathrm{H} 2 \mathrm{O}}$ could be explained by a difference in TP. During shaking, the friction of the sand could increase the $\mathrm{P}$ binding at particle surfaces, so that even after a very high number of repeated measuring processes the $P$ released from the sediment would not decrease, we therefore chose to perform the process when analyzing $\mathrm{P}_{\mathrm{H} 2 \mathrm{O}}$.

$10 \mathrm{~g}$ from each sediment sample were put into a centrifuge tube, mixed with $20 \mathrm{~mL} \mathrm{H}_{2} \mathrm{O}$ (aerobic desorption) and shaken for $2 \mathrm{~h}$ with an overhead shaker. After centrifuging for $5 \mathrm{~min}$, the supernatant was decanted and subsequently filtered to $0.45 \mu \mathrm{m}$ (Minisart ${ }^{\circledR}$ NML Syringe Filter, Sartorius, Göttingen, Germany). The desorption solution was diluted when needed, digested with $\mathrm{K}_{2} \mathrm{~S}_{2} \mathrm{O}_{8}$ in the digestion tube (autoclave) and the $\mathrm{P}_{\mathrm{H} 20}$ concentration was determined photometrically.

\subsubsection{Further Sediment Analysis}

Total P (TP), calcium (Ca), manganese $(\mathrm{Mn})$, Iron $(\mathrm{Fe})$, Aluminium $(\mathrm{Al})$ and lead $(\mathrm{Pb})$ were determined by ICP-OES, using $200 \mathrm{mg}$ grinded sample digested with $6 \mathrm{~mL} 65 \% \mathrm{HNO}_{3}$ and $2 \mathrm{~mL} 65 \%$ $\mathrm{HCl}$ in a high-pressure microwave oven.

\subsection{Growth Experiment}

Three different types of sediment were put in small $(\approx 2 \mathrm{dl})$ glass flasks: Pure sand as a control (C), sediment collected from the $\mathrm{N}$ shore of Lake Müggelsee and sediment collected from the $\mathrm{S}$ shore. Two tubers from S. pectinata (sampled from the N shore of Lake Müggelsee) were planted in each of the sediments, along with an artificial strip (transparent polypropylene; General Binding Corporation, Chicago, Illinois) serving as a substrate for periphyton growth sticking out $\approx 15 \mathrm{~cm}$ above the sediment surface (Figure 3). Before the tubers were planted their length and width were measured (Figure S2). With the assumption that the tubers have the shape of a prolate spheroid the volume was calculated using $4 / 3 \pi^{*}$ length ${ }^{*}$ width $^{2}$. There was no significant difference in tuber volume between the treatments (Kruskal-Wallis rank sum test). 


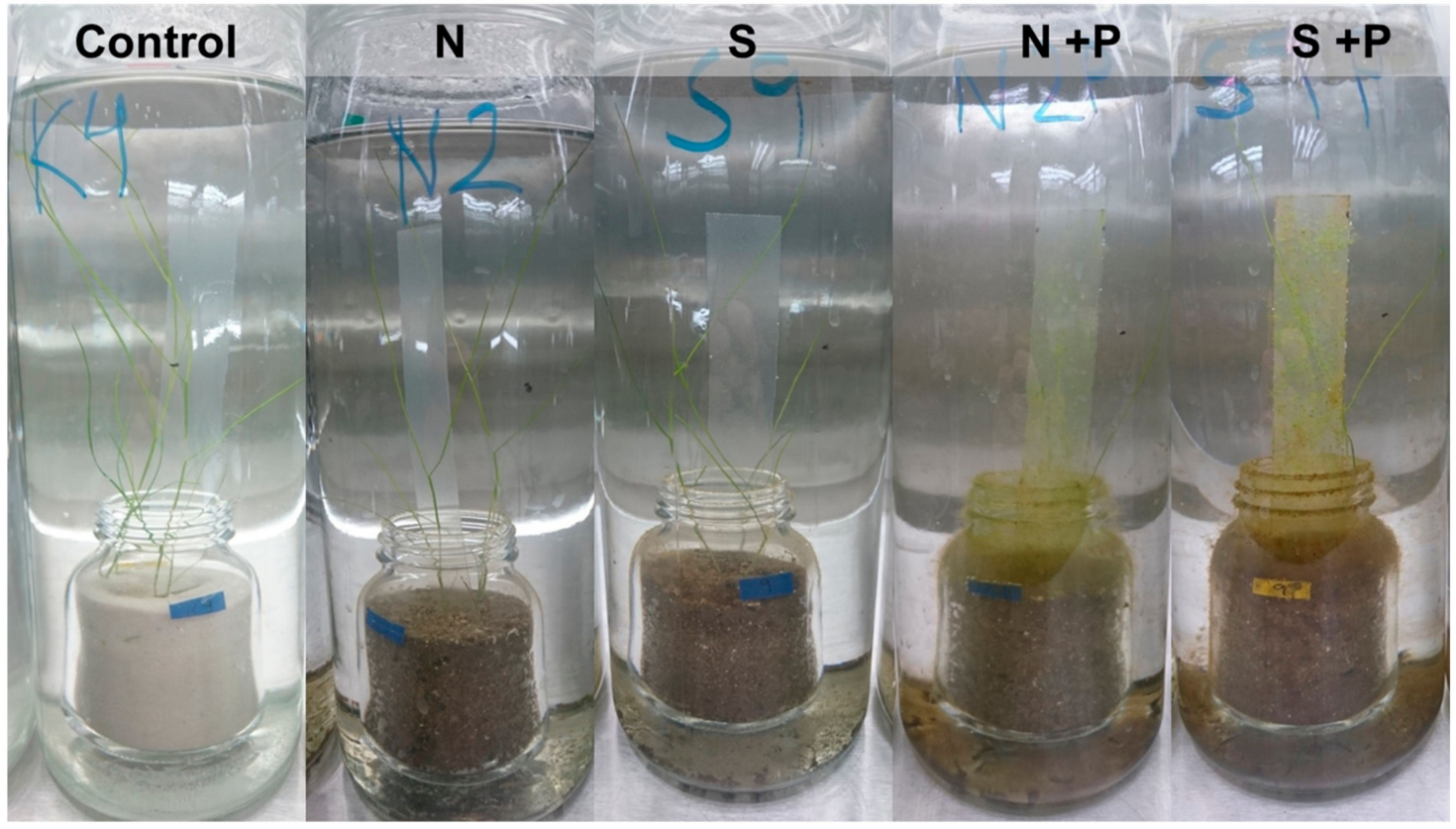

Figure 3. Experimental setup of the growth experiment with submerged macrophytes (Stuckenia pectinata) and periphyton on artificial substrates in five treatments (control: Sand, N, S: Sediments of north-eastern and south-western shore, respectively, +P: With phosphorus addition) with six replicates each.

The small glass flasks with sediment and tubers were put into $2 \mathrm{~L}$ bottles (Ikea Korken) filled with a nutrient solution after Körner and Nicklisch [27] that emulates the ionic composition of Lake Müggelsee, but without P. We ran five treatments (six replicates each): Controls, $\mathrm{N}$ and S sediment, and $\mathrm{N}$ and $\mathrm{S}$ sediment but with $\mathrm{P}$ addition to the nutrient solution in the form of monopotassium phosphate $\left(\mathrm{KH}_{2} \mathrm{PO}_{4}\right)$ to reach the concentration $0.1 \mathrm{mM}(\sim 320 \mu \mathrm{g} \mathrm{P} / \mathrm{L})$ (Figure 3). The combination of pure sand and $\mathrm{P}$ addition was omitted as it did not contain any periphytic algae inoculum.

The growth experiment was performed in a climate chamber at $20{ }^{\circ} \mathrm{C}\left(+/-0.5^{\circ} \mathrm{C}\right)$ under a $12 \mathrm{~h}$ light/dark regime for 21 days. This time-length was chosen to give sufficient time for the periphyton to develop but was held short enough to prevent nutrient depletion for the macrophytes that can initially use the nutrients stored in the tubers. Before starting the experiment, the light intensity was measured (TriOS GmbH, RAMSES-ASC-VIS) and 30 spots with similar light conditions $\left(92-112 \mathrm{~mW} / \mathrm{m}^{2} / \mathrm{nm}\right.$, median $=102 \mathrm{~mW} / \mathrm{m}^{2} / \mathrm{nm}$ ) were chosen for the placement of all bottles. The bottles were placed randomly, and their positions were changed randomly twice a week.

At the end of the experiment all plants were harvested, separated into roots and shoots, measured, dried in $60^{\circ} \mathrm{C}$ and weighed to determine final biomass. Before comparison and analysis the macrophyte biomass was divided with the tuber volume to account for the fact that tuber size determines macrophyte growth [28]. We used the entire macrophyte biomass for comparing treatment effects, however, we had to estimate the root weight of the control based on the correlation between shoot and root weight in the other treatments, because it was impossible to entirely remove the pure sand from the roots. Periphyton was scraped from the artificial substrates using a brush and by flushing nutrient solution. Aliquots of the suspension were filtrated onto pre-weighed filters (Whatman glass microfiber filters $\mathrm{GF} / \mathrm{F}$, diameter $25 \mathrm{~mm}$ ). Filters were dried at $60^{\circ} \mathrm{C}$ to weight constancy and final periphyton biomass determined from the difference between initial and final filter weight.

\subsection{Statistical Analysis}

Welch's t-test (when comparing data with unequal variability), Wilcoxon rank-sum test (when analyzing non-normal data) and Kruskal-Wallis test (multiple comparisons) were used for testing for 
significant differences between treatments. Correlations (Pearson product-moment correlation and Spearman's rank correlation) between macrophyte biomass and periphyton biomass were calculated using all treatments and macrophyte biomass above sediment.

We used multiple linear regression (MLR) with periphyton biomass as the dependent variable and $\mathrm{P}$ addition, $\mathrm{P}_{\mathrm{H} 2 \mathrm{O}}$ concentration in sediment, TP concentration in sediment, LOI, grainsize distribution (D10, D50) and lake side as independent variables. By using the Akaike information criterion and stepwise regression we found the most parsimonious model. We did the same with macrophyte biomass as the dependent variable and periphyton and the above-mentioned variables as independent variables. We also built a model where periphyton was the only independent variable explaining macrophyte growth. When necessary, data was log-transformed to meet the assumptions of normality.

We used the software R, version 3.5.0 for all statistical analysis and specifically the package ggplot2 [29] for plotting.

\section{Results}

\subsection{Sediment Characteristics}

In all the sediment samples, more than $99 \%$ of the non-organic material was sand. D10 values were not significantly different between samples from the $\mathrm{N}$ and the $\mathrm{S}$ shore (Figure 2B). The same holds for average values of D50, which were $0.389 \pm 0.021$ and $0.415 \pm 0.019 \mathrm{~mm}$, respectively. No significant difference in LOI and TP content was found between the samples of the $\mathrm{N}$ and S shore (Figure 2C, D).

The $\mathrm{P}_{\mathrm{H} 2 \mathrm{O}}$ content was significantly higher in the samples from the $\mathrm{N}$ shore than in the samples from the $S$ shore $(p=0.03$, Wilcoxon rank-sum test, Figure $2 E)$, while the opposite was found for the Fe content $(\mathrm{p}=0.015$, Wilcoxon rank-sum test, Figure $2 \mathrm{~F})$.

No significant difference in the $\mathrm{Al}, \mathrm{Ca}, \mathrm{Mg}, \mathrm{Mn}$ and $\mathrm{S}$ content was detected between the samples of the $\mathrm{N}$ and $\mathrm{S}$ shore (Figure $\mathrm{S} 3)$. The Pb content was below detection limit $(<0.01 \mathrm{mg} / \mathrm{g})$ in all samples.

\subsection{Growth Experiment}

Periphyton biomass was significantly higher in both treatments with lake sediments as compared to the control (white boxes in Figure $4 \mathrm{~A}, \mathrm{p}<0.01,95 \%$ confidence intervals: $[0.16,1.86]$ ( $\mathrm{N}$ vs. C) and $\mathrm{p}<0.01,95 \%$ confidence interval: $[0.28,1.04]$ (S vs. C)). Periphyton biomass was significantly higher in treatments with $\mathrm{P}$ additions to the water (grey boxes) as compared to treatments without $\mathrm{P}$ additions (Figures 3 and 4A, p < 0.001, $95 \%$ confidence interval: [1.35, 2.88], Wilcoxon rank-sum test), while periphyton biomass was not higher in treatments with sediment of the $\mathrm{N}$ shore containing more $\mathrm{P}_{\mathrm{H} 2 \mathrm{O}}$ (white boxes in Figure 4A). $\mathrm{P}_{\mathrm{H} 2 \mathrm{O}}$ contents and periphyton biomass were not significantly correlated. The linear regression model that best explained periphyton biomass contained both $\mathrm{P}$ addition to solution and content of $\mathrm{P}_{\mathrm{H} 2 \mathrm{O}}$ in sediment as independent variables, both positively contributing to periphyton biomass (adjusted $\mathrm{R}^{2}=0.63, \mathrm{p}<0.001$, Table S3).

Macrophyte biomass was not significantly different from controls in both treatments with sediments from $\mathrm{S}$ and $\mathrm{N}$ shore (Figure 4B). Macrophyte biomass was significantly lower when the tubers were grown in sediment samples from the $\mathrm{N}$ shore $(\mathrm{p}<0.05,95 \%$ confidence interval: $[-0.32,-0.03]$, Wilcoxon rank-sum test) as compared to when the tubers were grown in sediment samples from the $\mathrm{S}$ shore (Figure 4B). P additions resulted in significantly lower macrophyte biomass ( $p<0.05$, confidence interval: $[-0.208,-0.001]$, Wilcoxon rank-sum test). However, this effect is not significant when analyzing the treatments $\mathrm{N}$ and $\mathrm{S}$ individually (white and grey boxes, Figure 4B).

Macrophyte biomass was significantly negatively correlated with periphyton biomass (Spearman's rank correlation, $\varrho=-0.53, \mathrm{p}<0.01$, Figure 5). Periphyton had a negative impact on macrophyte biomass (adjusted $R^{2}=0.28, p<0.01$, Table $S 4$ ). 


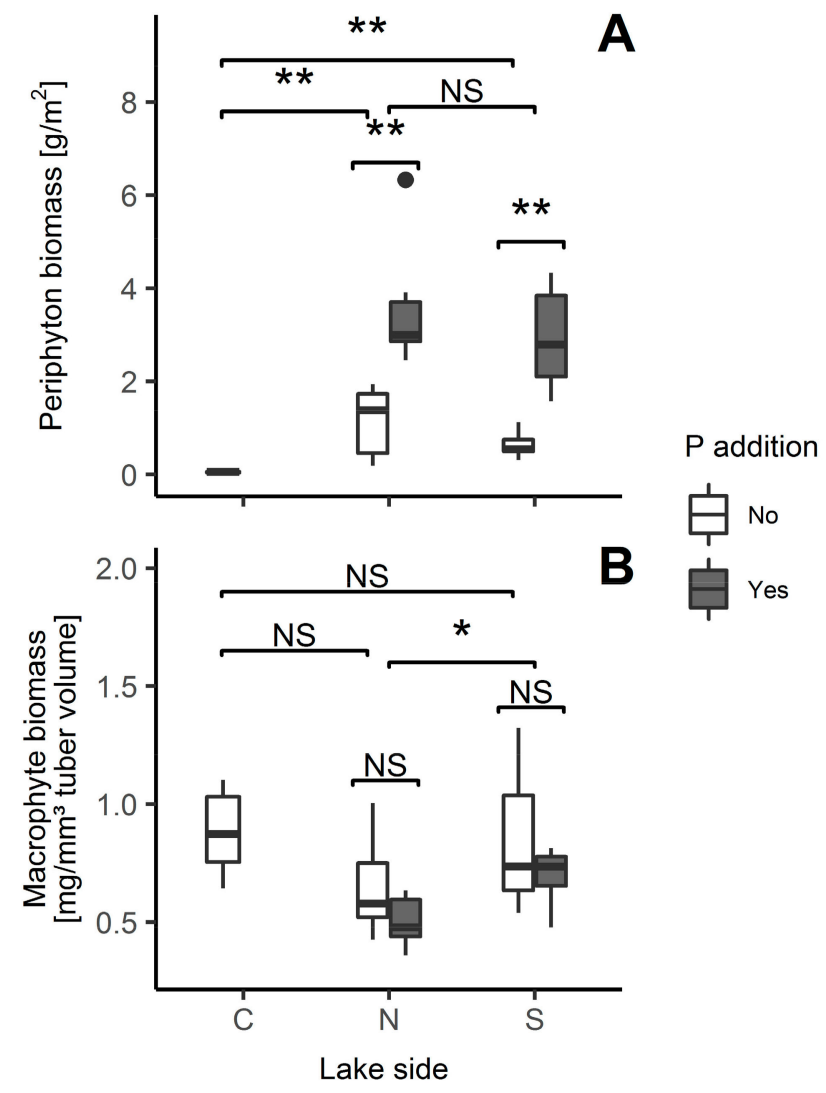

Figure 4. Final periphyton (A) and macrophyte (B) total biomass (dry weight) grown for 3 weeks in sediments sampled from north-eastern (N) and south-western (S) shores of Lake Müggelsee with and without $\mathrm{P}$ additions. The sediment used for the control $(\mathrm{C})$ treatment was pure sand and was only used without $\mathrm{P}$ additions. ${ }^{*}$ indicates a $\mathrm{p}$-value $<0.05,{ }^{* *}$ a $\mathrm{p}$-value $<0.01$ and NS a p-value $>0.05$.

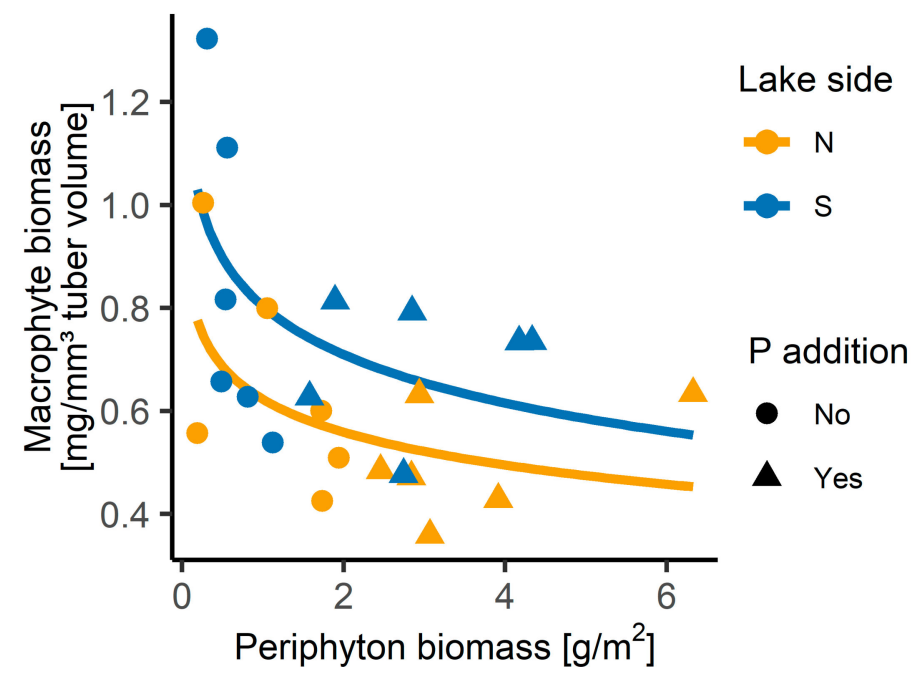

Figure 5. Final macrophyte biomass depending on periphyton biomass grown for 3 weeks on sediments from north-eastern $(\mathrm{N})$ and south-western $(\mathrm{S})$ shores of Lake Müggelsee with and without phosphorus $(\mathrm{P})$ addition. Lines indicate the logarithmic relation $(\mathrm{y}=\log (\mathrm{x}))$ between periphyton biomass $(\mathrm{x})$ and macrophyte biomass). 
The linear regression model that best explained total macrophyte biomass (excluding control) contained periphyton biomass ( $\log _{10}$-transformed) and lake shore as independent variables (adjusted $\mathrm{R}^{2}=0.35, \mathrm{p}<0.01$, Table S4).

\section{Discussion}

Our results show that the investigated sediments from different locations in the shallow sandy littoral of Lake Müggelsee did not differ in their content of organic matter, even though sediments of the $\mathrm{N}$ shore were more strongly affected by bank filtration. This process was expected to lead to an accumulation of organic material in sediment interstices. However, significantly higher values of water-soluble $\mathrm{P}_{\mathrm{H} 2 \mathrm{O}}$ in littoral sediments of the $\mathrm{N}$ shore were found as compared to sediments of $\mathrm{S}$ shore, explainable by either their lower Fe contents and/or an accumulation $\mathrm{P}_{\mathrm{H} 2 \mathrm{O}}$ due to a high biological turnover of organic material under the influence of IBF. Growth experiments revealed that additional $\mathrm{P}$ stimulated the growth of periphyton and that periphyton hampered macrophyte growth. Differences in P availability and growth of benthic primary producers in littoral lake sediments were thus found between samples taken from shores with low and high impacts of pumping wells. A causal link to bank filtration, however, could not be drawn and further mechanistic studies are required to explain the differences and to clarify the impact of IBF on benthic primary producers.

\subsection{Differences in Sediment Characteristics}

Contrary to our expectations, sediments of the $\mathrm{N}$ and $\mathrm{S}$ shore did not differ in their particle size distribution or organic matter content. The intensive pumping of the wells at the $\mathrm{N}$ shore of Lake Müggelsee and the fact that the uppermost sediment layer is very efficient in retaining particles with sizes down to $0.45 \mu \mathrm{m}$ during bank filtration [30] did thus not significantly influence the organic matter content, probably due to wave action clearing the pores. Organic matter content in littoral sediments affected by IBF of nearby Lake Tegel were found to be $1.5 \pm 0.5 \%$ of sediment dry weight in the upper $5 \mathrm{~cm}$ [31], which is about twice the content in this study.

An accumulation of fine organic material in coarse sandy sediments was probably prevented by a combination of sediment resuspension by wind (main wind direction in Berlin is from the southwest for most of the year [20]) and a high turnover of organic carbon by microbes and meiofauna of the interstices similar to what Hoffmann and Gunkel $[19,30]$ studied in Lake Tegel. Results of studies on accumulation of organic matter during infiltrating conditions can often differ (compare for example [19,30] with [32]) and deserve further research. In the sediment and the subsurface below an infiltration pond, organic carbon content was found to vary by two orders of magnitude [33]. Also, during operation a clogging layer with high organic carbon content was formed and after around four months it fully hindered infiltration through the pond bottom. This led to unsaturated conditions below the pond and increased mineralization of sedimentary particulate organic carbon [33]. Such conditions, however, seem unlikely at wind exposed bank filtration sites in Lake Müggelsee.

Our results showed a significantly higher content in $\mathrm{P}_{\mathrm{H} 2 \mathrm{O}}$ in sediment samples of the $\mathrm{N}$ shore, which was not explained by differences in TP content. One potential explanation is the higher Fe content in sediments of the $\mathrm{S}$ shore. $\mathrm{P}$ bound to Fe will not desorb when using an aerobic extractant such as water [34] unless it is loosely adsorbed [25]. P could also be bound by $\mathrm{Mn}, \mathrm{Al}, \mathrm{Ca}$ or S, but no difference in measured content was found between the $\mathrm{N}$ and $\mathrm{S}$ shores. Alternatively, or in addition, microbial mineralization of organic material accumulating in sediments during bank filtration could be responsible for the difference. This process has been described as being fast [18,19] and might result in a loading of the upper sediment layers with P. A similar accumulation of $\mathrm{P}$ in littoral areas has been described for invasive dreissenid mussels, which filter pelagic water and excrete P-rich faeces in benthic areas [35]. Dreissenid mussels, however, can filtrate the entire lake volume during one day [24,36], while bank filtration in Lake Müggelsee takes about a year for pumping the lake volume. More detailed biogeochemical analyses of the upper layers of sediments affected by bank filtration accompanied by experimental manipulations of the bank filtration intensity are needed to provide 
evidence for a causal relationship between bank filtration, $\mathrm{P}$ availability and binding forms in littoral lake sediments.

\subsection{Differences in Growth of Benthic Primary Producers}

Increased growth rates of periphyton after $\mathrm{P}$ addition to the water indicated a general growth limitation of periphyton by $\mathrm{P}$ in treatments without $\mathrm{P}$ addition. Final periphyton biomass was lower than values found in field experiments in River Spree flowing through Lake Müggelsee [37], but the periphyton biomass in treatments with $\mathrm{P}$ addition was higher than values reached on the same substrate in lab experiments simulating groundwater influxes to lakes [8], while periphyton biomass in treatments without $\mathrm{P}$ addition was similar or slightly lower. Differences in the availability of $\mathrm{P}_{\mathrm{H} 2 \mathrm{O}}$ in the sediments of the $\mathrm{N}$ and $\mathrm{S}$ shore still did not translate into different periphyton biomass in the experiment. This might have been caused by growth of benthic algae in and on the sediment that lowered $\mathrm{P}$ fluxes into the water and thus $\mathrm{P}$ availability for algae growth on plastic strips. Hoffmann and Gunkel [19] measured primary production in the top $2 \mathrm{~cm}$ in the sediments of the nearby Lake Tegel and found significant production by diatoms. Since interstitial algae were found to be abundant down to $6 \mathrm{~cm}$ sediment depth [31], the production is most certainly ongoing down to those depths as well. In addition, phytoplankton may have taken up part of the P released from sediments, but benthic algae covering the sediment surface should limit this process under sufficient light supply [38]. However, the most parsimonious model that explained periphyton growth did contain $\mathrm{P}_{\mathrm{H} 2 \mathrm{O}}$ as an explanatory variable, along with $\mathrm{P}$ addition. This indicates that diffusive fluxes of $\mathrm{P}_{\mathrm{H} 2 \mathrm{O}}$ from sediments into the water were still relevant for periphyton growth in our experiment. In lakes with a higher organic content in littoral sediments such as Lake Tegel [31], a higher P availability in interstices can be expected, potentially increasing the impact of diffusive P fluxes on periphyton growth. In the field, higher periphyton biomass has been shown to occur in an oligo-mesotrophic lake at locations with groundwater influx [11]. Whether diffusive $P$ fluxes from sandy littoral sediments are also relevant for periphyton biomass in eutrophic lakes remains to be proven.

Macrophyte growth was lower in the treatment using sediment from the $\mathrm{N}$ shore, where IBF pumping rates were higher. Furthermore, macrophyte growth was explained by periphyton growth and lake side in our most parsimonious model. While these findings generally confirm earlier findings on the negative effect of periphyton shading on macrophytes $[8,23,37,39]$, a strong causal link between the additional $\mathrm{P}$ availability in the $\mathrm{N}$ shore sediments and the lower macrophyte development via light attenuation by periphyton cannot be proven with our data. Shading effects by periphyton in the treatments without $\mathrm{P}$ addition to the water were low. In those treatments, the periphyton biomass reduced light availability by up to $19 \%$ using the formula provided in Köhler et al. [37]. Macrophytes are also facilitated by additional $\mathrm{P}$ availability in sediments, and this effect may have compensated for the additional shading effects by periphyton [7]. One could imagine that increased filtration would give a higher availability of dissolved inorganic nitrogen forms for plant growth. But that would lead to the opposite results from the ones we obtained in this study. Also, in the control treatment, where no nutrients at all were added, neither in the sediment nor in the nutrient solution, the macrophytes grew as much as in treatments with sediments collected from Lake Müggelsee. Therefore, there is no reason to believe, that the $\mathrm{S}$ or $\mathrm{N}$ treatments were more nitrogen limited than the control and therefore the role of nitrogen in the sediments, at least in our experimental setup, should have been negligible. Other factors potentially explaining the lower macrophyte growth on sediments of the $\mathrm{N}$ shore include exudates of dormant cyanobacteria that have been shown to negatively affect macrophyte seedling growth [40] pesticides or other organic micropollutants [41,42]. A high efficiency in removal of such substances during bank filtration has been shown recently [43] and consequently, an enrichment in sediments affected by bank filtration may occur and affect growth of benthic primary producers, but this topic was beyond the scope of this study. 


\section{Conclusions}

We could not confirm our first hypothesis that (1) littoral sediments in Lake Müggelsee affected by bank filtration showed a higher content of organic matter. But we could confirm that (2) those sediments had a higher P availability, (3) additional P stimulated periphyton growth and that (4) higher periphyton biomass hampered macrophyte growth. We conclude that significantly higher $\mathrm{P}_{\mathrm{H} 2 \mathrm{O}}$ contents and lower macrophyte growth can occur in littoral sandy lake sediments affected by bank filtration as compared to unaffected sites, but we cannot provide final evidence for a causal relationship between higher bank filtration rates, higher $\mathrm{P}_{\mathrm{H} 2 \mathrm{O}}$ content and lower macrophyte growth. However, our data suggest the potential for significant effects of induced bank filtration on sediments cascading to benthic primary producers that should receive more attention in future research to assure a sustainable application of this valuable drinking water production method.

Supplementary Materials: The following are available online at http://www.mdpi.com/2073-4441/11/5/1111/s1, Supplementary figures and tables.docx: Figure S1: Parameters of littoral sediment taken from two locations in Lake Müggelsee, Figure S2: Stuckenia pectinata tuber length and volume for each treatment, Figure S3: Parameters of littoral sediment taken from north-eastern (N) and south-western (S) shores, Table S1: Sample site coordinates, Table S2: Description of sediment samples, Table S3: Most parsimonious linear model explaining periphyton biomass, Table S4: Most parsimonious linear model explaining macrophyte biomass and linear model with periphyton biomass as the sole dependent variable explaining macrophyte biomass. Experimental data.xlsx: All data from sediment analysis and growth experiment.

Author Contributions: Conceptualization, M.G. and S.H.; data curation, M.G.; formal analysis, M.G.; funding acquisition, S.H.; investigation, M.G. and C.H.; methodology, M.G., C.H. and S.H.; project administration, M.G. and S.H.; resources, C.H. and S.H.; supervision, S.H.; validation, M.G., C.H. and S.H.; visualization, M.G.; writing-original draft, M.G. and S.H.; writing—review \& editing, M.G., C.H. and S.H.

Funding: This research was funded by the German Research Foundation grant number GRK 2032/1 (DFG research training group "Urban water interfaces"). The publication of this article was funded by the Open Access Fund of the Leibniz Association.

Acknowledgments: The authors would like to thank the members of the DFG (German Research Foundation) Research Training Group "Urban Water Interfaces" and the Berliner Wasserbetriebe, especially Dörte Siebenthaler, for her invaluable help during data collection. We are also grateful for the help from Michael Hupfer and other members of the chemical lab at IGB: Hans-Jürgen Exner, Jörg Gelbrecht, Tobias Goldhammer, Sylvia Jordan, Anne Linkert, Antje Lüder, Thomas Rossoll and Elisabeth Schütte, members of ecosystem research department at IGB: Marta Alirangues, Alexis Guislain, Liang He, Thomas Hintze, Garabet Kazanjian, Cécile Périllon, Simon Pötter and Benjamin Wegner as well as other persons that have been helpful during the work with this study: Thomas Petzoldt, Grit Siegert, Anna Stelmecke and Christof Engelhardt. We are thankful for the linguistic improvements made by Spencer Froelick.

Conflicts of Interest: The authors declare no conflict of interest. The funders had no role in the design of the study; in the collection, analyses, or interpretation of data; in the writing of the manuscript, or in the decision to publish the results.

\section{References}

1. Vadeboncoeur, Y.; Vander Zanden, M.J.; Lodge, D.M. Putting the Lake Back Together: Reintegrating Benthic Pathways into Lake Food Web Models. BioScience 2002, 52, 44-54. [CrossRef]

2. Hilt, S.; Brothers, S.; Jeppesen, E.; Veraart, A.J.; Kosten, S. Translating Regime Shifts in Shallow Lakes into Changes in Ecosystem Functions and Services. BioScience 2017, 67, 928-936. [CrossRef]

3. Brothers, S.M.; Hilt, S.; Meyer, S.; Köhler, J. Plant community structure determines primary productivity in shallow, eutrophic lakes. Freshw. Biol. 2013, 58, 2264-2276. [CrossRef]

4. Kazanjian, G.; Flury, S.; Attermeyer, K.; Kalettka, T.; Kleeberg, A.; Premke, K.; Köhler, J.; Hilt, S. Primary production in nutrient-rich kettle holes and consequences for nutrient and carbon cycling. Hydrobiologia 2018, 806, 77-93. [CrossRef]

5. Vadeboncoeur, Y.; McIntyre, P.B.; Vander Zanden, M.J. Borders of Biodiversity: Life at the Edge of the World's Large Lakes. Bioscience 2011, 61, 526-537. [CrossRef]

6. Elser, J.J.; Bracken, M.E.S.; Cleland, E.E.; Gruner, D.S.; Harpole, W.S.; Hillebrand, H.; Ngai, J.T.; Seabloom, E.W.; Shurin, J.B.; Smith, J.E. Global analysis of nitrogen and phosphorus limitation of primary producers in freshwater, marine and terrestrial ecosystems. Ecol. Lett. 2007, 10, 1135-1142. [CrossRef] [PubMed] 
7. Périllon, C.; Hilt, S. Groundwater influence differentially affects periphyton and macrophyte production in lakes. Hydrobiologia 2016, 778, 91-103. [CrossRef]

8. Périllon, C.; Hilt, S. Groundwater discharge gives periphyton a competitive advantage over macrophytes. Aquat. Bot. 2019, 154, 72-80. [CrossRef]

9. Phillips, G.; Willby, N.; Moss, B. Submerged macrophyte decline in shallow lakes: What have we learnt in the last forty years? Aquat. Bot. 2016, 135, 37-45. [CrossRef]

10. Boström, B.; Andersen, J.M.; Fleischer, S.; Jansson, M. Exchange of phosphorus across the sediment-water interface. Hydrobiologia 1988, 170, 229-244. [CrossRef]

11. Périllon, C.; Pöschke, F.; Lewandowski, J.; Hupfer, M.; Hilt, S. Stimulation of epiphyton growth by lacustrine groundwater discharge to an oligo-mesotrophic hard-water lake. Freshw. Sci. 2017, 36, 555-570. [CrossRef]

12. Gillefalk, M.; Massmann, G.; Nützmann, G.; Hilt, S. Potential Impacts of Induced Bank Filtration on Surface Water Quality: A Conceptual Framework for Future Research. Water 2018, 10, 1240. [CrossRef]

13. Ray, C.; Schubert, J.; Linsky, R.B.; Melin, G. Introduction. In Riverbank Filtration: Improving Source-Water Quality; Ray, C., Melin, G., Linsky, R.B., Eds.; Water science and technology library; Kluwer Acad. Publ.: Dordrecht, The Netherlands, 2003; pp. 1-15. ISBN 978-1-4020-1133-7.

14. Ray, C. Worldwide potential of riverbank filtration. Clean Technol. Environ. Policy 2008, 10, 223-225. [CrossRef]

15. Gillefalk, M.; Mooij, W.M.; Teurlincx, S.; Janssen, A.B.G.; Janse, J.H.; Chang, M.; Köhler, J.; Hilt, S. Modelling induced bank filtration effects on freshwater ecosystems to ensure sustainable drinking water production. Water Res. 2019, 157, 19-29. [CrossRef]

16. Périllon, C.; van de Weyer, K.; Päzolt, J.; Kasprzak, P.; Hilt, S. Changes in submerged macrophyte colonization in shallow areas of an oligo-mesotrophic lake and the potential role of groundwater. Limnologica 2018, 68, 168-176. [CrossRef]

17. Hagerthey, S.E.; Kerfoot, W.C. Spatial variation in groundwater-related resource supply influences freshwater benthic algal assemblage composition. J. N. Am. Benthol. Soc. 2005, 24, 807-819. [CrossRef]

18. Gunkel, G.; Hoffmann, A. Bank filtration of rivers and lakes to improve the raw water quality for drinking water supply. In Water Purification; Gertsen, N., Sønderby, L., Eds.; Air, water and soil pollution science and technology series; Nova Science Publishers: New York, NY, USA, 2009; pp. 137-169. ISBN 978-1-60741-599-2.

19. Hoffmann, A.; Gunkel, G. Carbon input, production and turnover in the interstices of a Lake Tegel bank filtration site, Berlin, Germany. Limnologica 2011, 41, 151-159. [CrossRef]

20. Driescher, E.; Behrendt, H.; Schellenberger, G.; Stellmacher, R. Lake Müggelsee and its environment-Natural conditions and anthropogenic impacts. Int. Rev. Gesamten Hydrobiol. 1993, 78, 327-343. [CrossRef]

21. Shatwell, T.; Köhler, J. Decreased nitrogen loading controls summer cyanobacterial blooms without promoting nitrogen-fixing taxa: Long-term response of a shallow lake. Limnol. Oceanogr. 2019, 64, S166-S178. [CrossRef]

22. Hilt, S.; Alirangues Nuñez, M.M.; Bakker, E.S.; Blindow, I.; Davidson, T.A.; Gillefalk, M.; Hansson, L.-A.; Janse, J.H.; Janssen, A.B.G.; Jeppesen, E.; et al. Response of Submerged Macrophyte Communities to External and Internal Restoration Measures in North Temperate Shallow Lakes. Front. Plant Sci. 2018, 9, 194. [CrossRef]

23. Roberts, E.; Kroker, J.; Körner, S.; Nicklisch, A. The role of periphyton during the re-colonization of a shallow lake with submerged macrophytes. Hydrobiologia 2003, 506, 525-530. [CrossRef]

24. Wegner, B. Quagga Mussel Invasion and Its Consequences in the Shallow Eutrophic LAKE Müggelsee, Berlin. Master's Thesis, Technical University, Berlin, Germany, 2018.

25. Hupfer, M.; Gächter, R.; Giovanoli, R. Transformation of phosphorus species in settling seston and during early sediment diagenesis. Aquat. Sci. 1995, 57, 305-324. [CrossRef]

26. Wünscher, R. A Comparison of Different Phosphorus Extraction Methods with the Phosphorus Uptake of Wheat. Master's Thesis, Universität für Bodenkultur Wien, Vienna, Austria, 2013.

27. Körner, S.; Nicklisch, A. Allelopathic growth inhibition of selected phytoplankton species by submerged macrophytes. J. Phycol. 2002, 38, 862-871. [CrossRef]

28. Vermaat, J.E.; Hootsmans, M.J.M. Intraspecific variation in Potamogeton pectinatus L.: A controlled laboratory experiment. In Lake Veluwe, a Macrophyte-Dominated System under Eutrophication Stress; van Vierssen, W., Hootsmans, M.J.M., Vermaat, J.E., Eds.; Springer: Dordrecht, The Netherlands, 1994; pp. 26-39.

29. Wickham, H. ggplot2: Elegant Graphics for Data Analysis, 2nd ed.; Springer: Cham, Switzerland, 2016; ISBN 978-3-319-24277-4. 
30. Hoffmann, A.; Gunkel, G. Bank filtration in the sandy littoral zone of Lake Tegel (Berlin): Structure and dynamics of the biological active filter zone and clogging processes. Limnologica 2011, 41, 10-19. [CrossRef]

31. Gunkel, G.; Beulker, C.; Hoffmann, A.; Kosmol, J. Fine particulate organic matter (FPOM) transport and processing in littoral interstices-Use of fluorescent markers. Limnologica 2009, 39, 185-199. [CrossRef]

32. Salamon, E.; Goda, Z. Coupling Riverbank Filtration with Reverse Osmosis May Favor Short Distances between Wells and Riverbanks at RBF Sites on the River Danube in Hungary. Water 2019, 11, 113. [CrossRef]

33. Greskowiak, J.; Prommer, H.; Massmann, G.; Johnston, C.D.; Nützmann, G.; Pekdeger, A. The impact of variably saturated conditions on hydrogeochemical changes during artificial recharge of groundwater. Appl. Geochem. 2005, 20, 1409-1426. [CrossRef]

34. Psenner, R.; Pucsko, R.; Sager, M. Fractionation of organic and inorganic phosphorous compounds in lake sediments, An attempt to characterize ecologically important fractions. Arch. Hydrobiol. 1984, 70, 111-155.

35. Hecky, R.E.; Smith, R.E.; Barton, D.R.; Guildford, S.J.; Taylor, W.D.; Charlton, M.N.; Howell, T. The nearshore phosphorus shunt: A consequence of ecosystem engineering by dreissenids in the Laurentian Great Lakes. Can. J. Fish. Aquat. Sci. 2004, 61, 1285-1293. [CrossRef]

36. Noordhuis, R.; van Zuidam, B.G.; Peeters, E.T.H.M.; van Geest, G.J. Further improvements in water quality of the Dutch Borderlakes: Two types of clear states at different nutrient levels. Aquat. Ecol. 2016, 50, 521-539. [CrossRef]

37. Köhler, J.; Hachoł, J.; Hilt, S. Regulation of submersed macrophyte biomass in a temperate lowland river: Interactions between shading by bank vegetation, epiphyton and water turbidity. Aquat. Bot. 2010, 92, 129-136. [CrossRef]

38. Jäger, C.G.; Diehl, S. Resource competition across habitat boundaries: Asymmetric interactions between benthic and pelagic producers. Ecol. Monogr. 2014, 84, 287-302. [CrossRef]

39. Jones, J.I.; Sayer, C.D. Does the Fish-Invertebrate-Periphyton Cascade Precipitate Plant Loss in Shallow Lakes? Ecology 2003, 84, 2155-2167. [CrossRef]

40. Xu, R.; Hilt, S.; Pei, Y.; Yin, L.; Wang, X.; Chang, X. Growth phase-dependent allelopathic effects of cyanobacterial exudates on Potamogeton crispus L. seedlings. Hydrobiologia 2016, 767, 137-149. [CrossRef]

41. Fernandez, R.T.; Whitwell, T.; Riley, M.B.; Bernard, C.R. Evaluating semiaquatic herbaceous perennials for use in herbicide phytoremediation. J. Am. Soc. Hortic. Sci. 1999, 124, 539-544. [CrossRef]

42. Knuteson, S.L.; Whitwell, T.; Klaine, S.J. Influence of plant age and size on simazine toxicity and uptake. J. Environ. Qual. 2002, 31, 2096-2103. [CrossRef] [PubMed]

43. Dragon, K.; Górski, J.; Kruć, R.; Drożdżyński, D.; Grischek, T. Removal of Natural Organic Matter and Organic Micropollutants during Riverbank Filtration in Krajkowo, Poland. Water 2018, 10, 1457. [CrossRef] 